\title{
Numerical Investigation on Magnetohydrodynamics (MHD) Free Convection Fluid Flow over a Vertical Porous Plate with induced Magnetic Field
}

\author{
Ronju Khatun, Mohammad Roknujjaman, Mohammad Abdul Al Mohit \\ Department of Mathematics, Islamic University (IU), Kushtia, Bangladesh \\ Email address: \\ ronjukhatun@gmail.com(R.Khatun),rkripon.mathiu@gmail.com(M. Roknujjaman),mohit@math.iu.ac.bd(M.A.Al Mohit) \\ To cite this article: \\ Ronju Khatun, Mohammad Roknujjaman, Mohammad Abdul Al Mohit. Numerical Investigation on Magnetohydrodynamics (MHD) Free \\ Convection Fluid Flow over a Vertical Porous Plate with induced Magnetic Field. International Journal of Applied Mathematics and \\ Theoretical Physics. Vol. 4, No. 1, 2018, pp. 15-26. doi: 10.11648/j.ijamtp.20180401.13
}

Received: March 8, 2018; Accepted: April 2, 2018; Published: May 10, 2018

\begin{abstract}
In this paper, investigate a two dimensional unsteady Magneto hydro dynamics (MHD) free convection flow of viscous incompressible and electrically conducting fluid flow past an vertical plate in the presence of Grashof Number, Modified Grashof Number, Prandtl Number, Schamidt Number as well as Dufour effects. The governing equations of the problem contain a system of non-linear partial differential equations; have been transformed into a set of coupled non-linear ordinary differential equations which is solved numerically by applying well known explicit finite difference method. The Finite-difference method is an enormously used technique to investigate of the general non linear partial differential equation. Partial differential equations occur in many branches of applied mathematics for example, in hydrodynamics, elasticity, quantum mechanics. Hence, the proposed study is to investigate the numerical results which are performed for various physical parameters such as velocity profiles, temperature distribution and concentration profiles within the boundary layer are separately discussed in graphically.
\end{abstract}

Keywords: MHD, Non-Linear PDE, Rotating System, Mass and Heat Transfer, Explicit Finite Difference Method

\section{Introduction}

MHD boundary layer flow has become significant applications in industrial manufacturing processes such as plasma studies, petroleum industries Magneto hydrodynamics power generator cooling of clear reactors, boundary layer control in aerodynamics. Many authors have studied the effects of magnetic field on mixed, natural and force convection heat and mass transfer problems.

A. S. Idowu et al [1] studied the radiation effect on unsteady heat and mass transfer of MHD and dissipative fluid flow past a moving vertical porous plate with variable suction in the presence of heat generation and chemical reaction. M. S. Alam et al [2] studied the free convective heat and mass transfer flow past an inclined semi infinite heated surface of an electrically conducting and steady viscous incompressible fluid in the presence of a magnetic field and heat generation. Mohammad Shah Alam et al [3] investigated the Hall effects on the steady MHD free-convective flow and mass transfer over an inclined stretching sheet in the presence of a uniform magnetic field. M. Umamaheswar et al [4] reported an unsteady magneto hydrodynamic free convective, Visco-elastic, dissipative fluid flow embedded in porous medium bounded by an infinite inclined porous plate in the presence of heat source, P. R. Sharma et al [5] investigated the flow of a viscous incompressible electrically conducting fluid along a porous vertical isothermal nonconducting plate with variable suction and internal heat generation in the presence of transverse magnetic field. Hemant Poonia and R. C. Chaudhary [6] analyzed the heat and mass transfer effects on an unsteady two dimensional laminar mixed convective boundary layer flow of viscous, incompressible, electrically conducting fluid, along a vertical plate with suction, embedded in porous medium, in the presence of transverse magnetic field and the effects of the viscous dissipation. C. V. Ramana Kumari and N. Bhaskara Reddy [7] reported an analytical analysis of mass transfer effects of unsteady free convective flow past an infinite, 
vertical porous plate with variable suctionReddy et al [8]. K. Bhagya Lakshmi et al [9] investigated the hydromagnetic effects on the unsteady free convection flow, heat and mass transfer characteristics in a viscous, incompressible and electrically conducting fluid past an exponentially accelerated vertical plate and the heat due to viscous dissipation.

Seethamahalakshmi et al [10] investigated an unsteady free convection flow and mass transfer of an optically thin viscous, electrically conducting incompressible fluid near an infinite vertical plate which moves with time dependent velocity in presence of transverse uniform magnetic field and thermal radiation. V. Rajesh [11] examined the effects of temperature dependent heat source on the unsteady free convection and mass transfer flow of an Elasto-viscous fluid past an exponentially accelerated infinite vertical plate in the presence of magnetic field through porous medium. $\mathrm{N}$. Bhaskar Reddy et al [12] discussed the MHD effects on the unsteady heat and mass transfer convective flow past an infinite vertical porous plate with variable suction. Nisat Nowroz Anika et al [13] studied the roll of magnetic field on ionized Magnetohydrodynamic fluid flow through an infinite rotating vertical porous plate with heat transfer.

Mohammad Shah Alam et al [14] investigated Hall effects on the steady MHD free-convective flow and mass transfer over an inclined stretching sheet in the presence of a uniform magnetic field. Joseph K. M et al [15] considered one dimensional couette flow of an electrically conducting fluid between two infinite parallel porous plates under the influence of inclined magnetic field with heat transfer. Consider the thermal radiation interaction with unsteady MHD flow past rapidly moving plate has a great important application in different brance of science and to the chemical engineering processes and in many technological fields. This types of problems were studied by Abdulwaheed Jimoh[16], Rasulalizadehand Alirezadarvish [17]. Numerical solution of MHD fluid flow past an infinite vertical porous plate was done by K. Anitha [18]. Takhar and Ram [19] studied the effects of Hall current on hydro-magnetic free convective flow through a porous medium. Chaudhary and Sharma [20] have analytically analyzed the steady combined heat and mass transfer flow with induced magnetic field. The aim of this paper is to investigate numerically transient MHD combined heat and mass transfer by mixed convection flow over a continuously moving vertical porous plate under the action of strong magnetic field taking into account the induced magnetic field with constant heat and mass fluxes. The governing equations of the problem contain a system of partial differential equations which are transfomed by usual transformation into a non-dimensional system of partial coupled non-linear differential equations. The obtained non-similar partial differential equations will be solved numerically by finite difference method. The results of this study will be discussed for the different values of the well known parameters and will be shown graphically.

\section{Mathematical Model of the Flow}

MHD power generation system combined heat and mass transfer in natural convective flows on moving vertical porous plate with thermal diffusion is considered. Let, the $x$ axis is chosen along the porous plate in the direction of flow and the $y$-axis is normal to the plate. The MHD transfer flow under the action of a strong megnetic field. The form of the induced magnetic field is $\left(B_{x}, B_{y}, 0\right)$. Now the Maxwell's equation is $\nabla . B=0$ so the megnatic field becomes $B_{y}=B_{0}$.

Initially, consider that the plate as well as the fluid are at the same temperature $T\left(=T_{\infty}\right)$ and the concentration level $C\left(=C_{\infty}\right)$ everywhere in the fluid is same. Also it is assumed that the fluid and the plate is at rest after that the plate is to be moving with a constant velocity $U_{0}$ in its own plane and instantaneously at time $t>0$, the temperature of the plate and the species concentration are raised to $T_{w}\left(>T_{\infty}\right)$ and $C_{w}\left(>C_{\infty}\right)$ respectively, which are thereafter maintained constant, where $T_{w}, C_{w}$ are the temperature and species concentration at the wall and $T_{\infty}, C_{\infty}$ are the temperature and concentration of the species far away from the plate respectively.

The physical model of this study is furnished in the following figure.

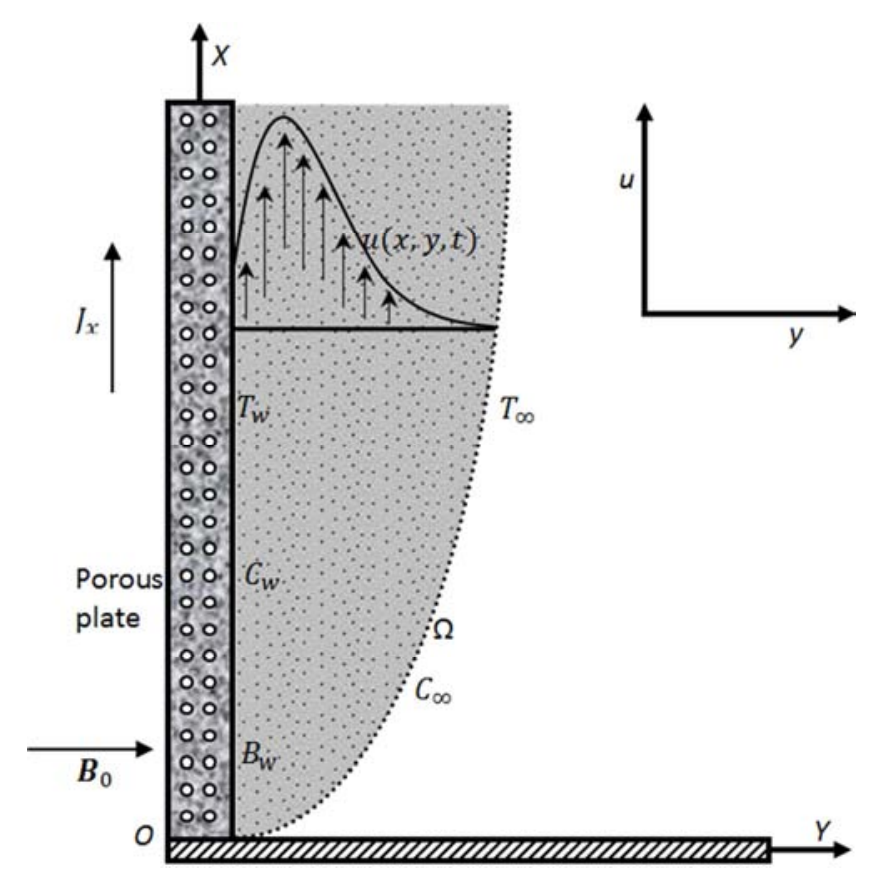

Figure 1. Physical configuration and coordinate system.

Continuity equation

$$
\frac{\partial u}{\partial x}+\frac{\partial v}{\partial y}=0
$$

Momentum equation

$$
\begin{gathered}
\frac{\partial u}{\partial t}+u \frac{\partial u}{\partial x}+v \frac{\partial u}{\partial y}=\mathrm{g} \beta\left(T-T_{\infty}\right)+\mathrm{g} \beta^{*}\left(C-C_{\infty}\right)+v \frac{\partial^{2} u}{\partial y^{2}}- \\
\frac{\sigma^{\prime} \mathrm{B}_{0}{ }^{2} \mathrm{u}}{\rho}
\end{gathered}
$$




$$
\frac{\partial w}{\partial t}+u \frac{\partial w}{\partial x}+v \frac{\partial w}{\partial y}=\vartheta \frac{\partial^{2} w}{\partial y^{2}}+\frac{\sigma^{\prime} \mathrm{B}_{0}^{2} \mathrm{w}}{\rho}
$$

MHD energy equation

$$
\frac{\partial T}{\partial t}+u \frac{\partial T}{\partial x}+v \frac{\partial T}{\partial y}=\frac{\kappa}{\rho c_{p}} \frac{\partial^{2} T}{\partial y^{2}}+\frac{\mathrm{D}_{\mathrm{m}} \mathrm{k}_{\mathrm{T}}}{\mathrm{C}_{\mathrm{s}} \mathrm{C}_{\mathrm{p}}} \frac{\partial^{2} C}{\partial y^{2}}
$$

Concentration equation

$$
\frac{\partial C}{\partial t}+u \frac{\partial C}{\partial x}+v \frac{\partial C}{\partial y}=D_{m} \frac{\partial^{2} C}{\partial y^{2}}
$$

With the corresponding initial and boundary conditions are

$$
\begin{gathered}
u=0, w=0, T=T_{w}, C=C_{w} \text { at } y=0 \\
u=0, w=0, T \rightarrow T_{\infty}, C \rightarrow C_{\infty} \text { as } y \rightarrow \infty
\end{gathered}
$$

\section{Mathematical Formulation}

Since the solutions of the governing equations (1)-(4) under the initial (6) and boundary (7) conditions will be based on the finite difference method it is required to make the said equations dimensionless. For this purpose, now introduce the following dimensionless quantities;

$$
\begin{gathered}
X=\frac{x U_{0}}{\vartheta}, Y=\frac{y U_{0}}{\vartheta}, \mathrm{U}=\frac{u}{U_{0}}, \mathrm{~V}=\frac{v}{U_{0}}, \mathrm{~W}=\frac{w}{U_{0}}, \tau=\frac{t U_{0}^{2}}{\vartheta} \\
\overline{B_{0}}=\sqrt{\frac{\mu_{e}}{\rho}} \frac{B_{0}}{U_{0}}, \bar{T}=\frac{T-T_{\infty}}{T_{w}-T_{\infty}}, \bar{C}=\frac{C-C_{\infty}}{C_{w}-C_{\infty}} .
\end{gathered}
$$

From the above dimensionless variable

$$
\begin{gathered}
\mathrm{x}=\frac{\vartheta X}{U_{0}}, \mathrm{y}=\frac{\vartheta Y}{U_{0}}, \mathrm{u}=U_{0} U, \mathrm{v}=U_{0} V, \mathrm{w}=U_{0} W, B_{0}=U_{0} \sqrt{\frac{\rho}{\mu_{e}}} \overline{B_{0}} \\
\mathrm{~T}=T_{\infty}+\left(T_{w}-T_{\infty}\right) \bar{T} \text { and } \mathrm{C}=C_{\infty}+\left(C_{w}-C_{\infty}\right) \bar{C} .
\end{gathered}
$$

Using these relations the following derivatives

$$
\begin{gathered}
\frac{\partial u}{\partial t}=\frac{\partial u}{\partial \tau} \frac{\partial \tau}{\partial t}=\frac{\partial\left(U_{0} U\right)}{\partial \tau} \frac{\partial}{\partial t}\left(\frac{t U_{0}^{2}}{\vartheta}\right)=\frac{U_{0}^{3}}{\vartheta} \frac{\partial U}{\partial \tau} \\
\frac{\partial u}{\partial x}=\frac{\partial u}{\partial X} \frac{\partial X}{\partial x}=\frac{\partial\left(U_{0} U\right)}{\partial X} \frac{\partial}{\partial x}\left(\frac{x U_{0}}{\vartheta}\right)=\frac{U_{0}^{2}}{\vartheta} \frac{\partial U}{\partial X} \\
\frac{\partial u}{\partial y}=\frac{\partial u}{\partial Y} \frac{\partial Y}{\partial y}=\frac{\partial\left(U_{0} U\right)}{\partial Y} \frac{\partial}{\partial y}\left(\frac{y U_{0}}{\vartheta}\right)=\frac{U_{0}^{2}}{\vartheta} \frac{\partial U}{\partial Y} \\
\frac{\partial^{2} u}{\partial y^{2}}=\frac{\partial}{\partial y}\left(\frac{\partial u}{\partial y}\right)=\frac{\partial}{\partial Y}\left(\frac{U_{0}^{2}}{\vartheta} \frac{\partial U}{\partial Y}\right) \frac{\partial Y}{\partial y}=\frac{\partial}{\partial Y}\left(\frac{U_{0}^{2}}{\vartheta} \frac{\partial U}{\partial Y}\right) \frac{\partial}{\partial y}\left(\frac{y U_{0}}{\vartheta}\right)=\frac{U_{0}^{3}}{\vartheta^{2}} \frac{\partial^{2} U}{\partial Y^{2}} \\
\frac{\partial w}{\partial t}=\frac{\partial w}{\partial \tau} \frac{\partial \tau}{\partial t}=\frac{\partial\left(U_{0} W\right)}{\partial \tau} \frac{\partial}{\partial t}\left(\frac{t U_{0}^{2}}{\vartheta}\right)=\frac{U_{0}^{3}}{\vartheta} \frac{\partial W}{\partial \tau} \\
\frac{\partial w}{\partial y}=\frac{\partial w}{\partial X} \frac{\partial X}{\partial x}=\frac{\partial\left(U_{0} W\right)}{\partial X} \frac{\partial}{\partial x}\left(\frac{x U_{0}}{\vartheta}\right)=\frac{U_{0}^{2}}{\vartheta} \frac{\partial W}{\partial X}=\frac{\partial\left(U_{0} W\right)}{\partial Y} \frac{\partial}{\partial y}\left(\frac{y U_{0}}{\vartheta}\right)=\frac{U_{0}^{2}}{\vartheta} \frac{\partial W}{\partial Y} \\
\frac{\partial^{2} w=\frac{\partial}{\partial y^{2}}\left(\frac{\partial w}{\partial y}\right)=}{\partial Y}\left(\frac{U_{0}^{2}}{\vartheta} \frac{\partial W}{\partial Y}\right) \frac{\partial Y}{\partial y}=\frac{\partial}{\partial Y}\left(\frac{U_{0}^{2}}{\vartheta} \frac{\partial W}{\partial Y}\right) \frac{\partial}{\partial y}\left(\frac{y U_{0}}{\vartheta}\right)=\frac{U_{0}^{3}}{\vartheta^{2}} \frac{\partial^{2} W}{\partial Y^{2}} \\
\frac{\partial T}{\partial t}=\frac{\partial T}{\partial \tau} \frac{\partial \tau}{\partial t}=\frac{\partial\left\{T_{\infty}+\left(T_{w}-T_{\infty}\right) \bar{T}\right\}}{\partial \tau} \frac{\partial}{\partial t}\left(\frac{t U_{0}^{2}}{\vartheta}\right)=\frac{U_{0}^{2}\left(T_{w}-T_{\infty}\right)}{\vartheta} \frac{\partial \bar{T}}{\partial \tau}
\end{gathered}
$$

$$
\begin{gathered}
\frac{\partial T}{\partial x}=\frac{\partial T}{\partial X} \frac{\partial X}{\partial x}=\frac{\partial\left\{T_{\infty}+\left(T_{w}-T_{\infty}\right) \bar{T}\right\}}{\partial X} \frac{\partial}{\partial x}\left(\frac{x U_{0}}{\vartheta}\right)=\frac{U_{0}\left(T_{w}-T_{\infty}\right)}{\vartheta} \frac{\partial \bar{T}}{\partial X} \\
\frac{\partial T}{\partial y}=\frac{\partial T}{\partial Y} \frac{\partial Y}{\partial y}=\frac{\partial\left\{T_{\infty}+\left(T_{w}-T_{\infty}\right) \bar{T}\right\}}{\partial Y} \frac{\partial}{\partial y}\left(\frac{y U_{0}}{\vartheta}\right)=\frac{U_{0}\left(T_{w}-T_{\infty}\right)}{\vartheta} \frac{\partial \bar{T}}{\partial Y} \\
\frac{\partial^{2} T}{\partial y^{2}}=\frac{\partial}{\partial y}\left(\frac{\partial T}{\partial y}\right)=\frac{\partial}{\partial Y}\left(\frac{U_{0}\left(T_{w}-T_{\infty}\right)}{\vartheta} \frac{\partial \bar{T}}{\partial Y}\right) \frac{\partial Y}{\partial y}= \\
\frac{\partial}{\partial Y}\left(\frac{U_{0}\left(T_{w}-T_{\infty}\right)}{\vartheta} \frac{\partial \bar{T}}{\partial Y}\right) \frac{\partial}{\partial y}\left(\frac{y U_{0}}{\vartheta}\right) \\
=\frac{U_{0}^{2}\left(T_{w}-T_{\infty}\right)}{\vartheta} \frac{\partial^{2} \bar{T}}{\partial Y^{2}} \\
\frac{\partial C}{\partial t}=\frac{\partial C}{\partial \tau} \frac{\partial \tau}{\partial t}=\frac{\partial\left\{C_{\infty}+\left(C_{w}-C_{\infty}\right) \bar{C}\right\}}{\partial \tau} \frac{\partial}{\partial t}\left(\frac{t U_{0}^{2}}{\vartheta}\right)=\frac{U_{0}^{2}\left(C_{w}-C_{\infty}\right)}{\vartheta} \frac{\partial \bar{C}}{\partial \tau} \\
\frac{\partial C}{\partial x}=\frac{\partial C}{\partial X} \frac{\partial X}{\partial x}=\frac{\partial\left\{C_{\infty}+\left(C_{w}-C_{\infty}\right) \bar{C}\right\}}{\partial X} \frac{\partial}{\partial x}\left(\frac{x U_{0}}{\vartheta}\right)=\frac{U_{0}\left(C_{w}-C_{\infty}\right)}{\vartheta} \frac{\partial \bar{C}}{\partial X} \\
\frac{\partial C}{\partial y}=\frac{\partial C}{\partial Y} \frac{\partial Y}{\partial y}=\frac{\partial\left\{C_{\infty}+\left(C_{w}-C_{\infty}\right) \bar{C}\right\}}{\partial Y} \frac{\partial}{\partial y}\left(\frac{y U_{0}}{\vartheta}\right)=\frac{U_{0}\left(C_{w}-C_{\infty}\right)}{\vartheta} \frac{\partial \bar{C}}{\partial Y}
\end{gathered}
$$

And

$$
\begin{gathered}
\frac{\partial^{2} C}{\partial y^{2}}=\frac{\partial}{\partial y}\left(\frac{\partial C}{\partial y}\right)=\frac{\partial}{\partial Y}\left(\frac{U_{0}\left(C_{w}-C_{\infty}\right)}{\vartheta} \frac{\partial \bar{C}}{\partial Y}\right) \frac{\partial Y}{\partial y}= \\
\frac{\partial}{\partial Y}\left(\frac{U_{0}\left(C_{w}-C_{\infty}\right)}{\vartheta} \frac{\partial \bar{C}}{\partial Y}\right) \frac{\partial}{\partial y}\left(\frac{y U_{0}}{\vartheta}\right) \\
=\frac{U_{0}^{2}\left(C_{w}-C_{\infty}\right)}{\vartheta^{2}} \frac{\partial^{2} \bar{C}}{\partial Y^{2}}
\end{gathered}
$$

Now substitute the values of the above derivatives into the equations (1)-(5) and after simplification obtain the following nonlinear coupled partial differential equations interms of dimensionless variables

$$
\begin{gathered}
\frac{\partial U}{\partial X}+\frac{\partial V}{\partial Y}=0 \\
\frac{\partial U}{\partial \tau}+\mathrm{U} \frac{\partial U}{\partial X}+\mathrm{V} \frac{\partial U}{\partial Y}=G_{r} \bar{T}+G_{m} \bar{C}+\frac{\partial^{2} U}{\partial Y^{2}}-M U \\
\frac{\partial W}{\partial \tau}+\mathrm{U} \frac{\partial W}{\partial X}+\mathrm{V} \frac{\partial W}{\partial Y}=\frac{\partial^{2} W}{\partial Y^{2}}+M W \\
\frac{\partial \bar{T}}{\partial \tau}+\mathrm{U} \frac{\partial \bar{T}}{\partial X}+\mathrm{V} \frac{\partial \bar{T}}{\partial Y}=\frac{1}{P_{r}} \frac{\partial^{2} \bar{T}}{\partial Y^{2}}+D_{u} \frac{\partial^{2} \bar{C}}{\partial Y^{2}} \\
\frac{\partial \bar{C}}{\partial \tau}+\mathrm{U} \frac{\partial \bar{C}}{\partial X}+\mathrm{V} \frac{\partial \bar{C}}{\partial Y}=\frac{1}{S_{c}} \frac{\partial^{2} \bar{C}}{\partial Y^{2}}
\end{gathered}
$$

Where

$$
\begin{gathered}
G_{r}=\frac{\vartheta \mathrm{g} \beta\left(T_{w}-T_{\infty}\right)}{U_{0}^{3}}(\text { Grashof Number }), \\
G_{m}=\frac{\vartheta \mathrm{g} \beta^{*}\left(T_{w}-T_{\infty}\right)}{U_{0}^{3}}(\text { Modified Grashof Number }), \\
\mathrm{M}=\frac{\sigma \vartheta B_{0}^{2}}{\rho U_{0}^{2}}(\text { Magnetic Parameter }), \\
P_{r}=\frac{\vartheta \rho C_{p}}{\kappa}(\text { Prandtl Number }) \\
S_{c}=\frac{\vartheta}{D_{m}}(\text { Schmidt Number })
\end{gathered}
$$

And 


$$
D_{u}=\frac{\vartheta D_{m} \kappa_{T}\left(C_{w}-C_{\infty}\right)}{C_{S} C_{p}\left(T_{w-} T_{\infty}\right)}(\text { Dufour Number })
$$

Also the associated initial (6) and boundary (7) conditions become

$$
\begin{aligned}
& U=0, W=0, \bar{T}=1, \bar{C}=1 \text { at } Y=0 \\
& U=0, W=0, \bar{T}=0, \bar{C}=0 \text { as } Y=0
\end{aligned}
$$

\section{Numerical Solutions}

To solve the second order non-linear coupled dimensionless partial differential equations (8)-(12) with the

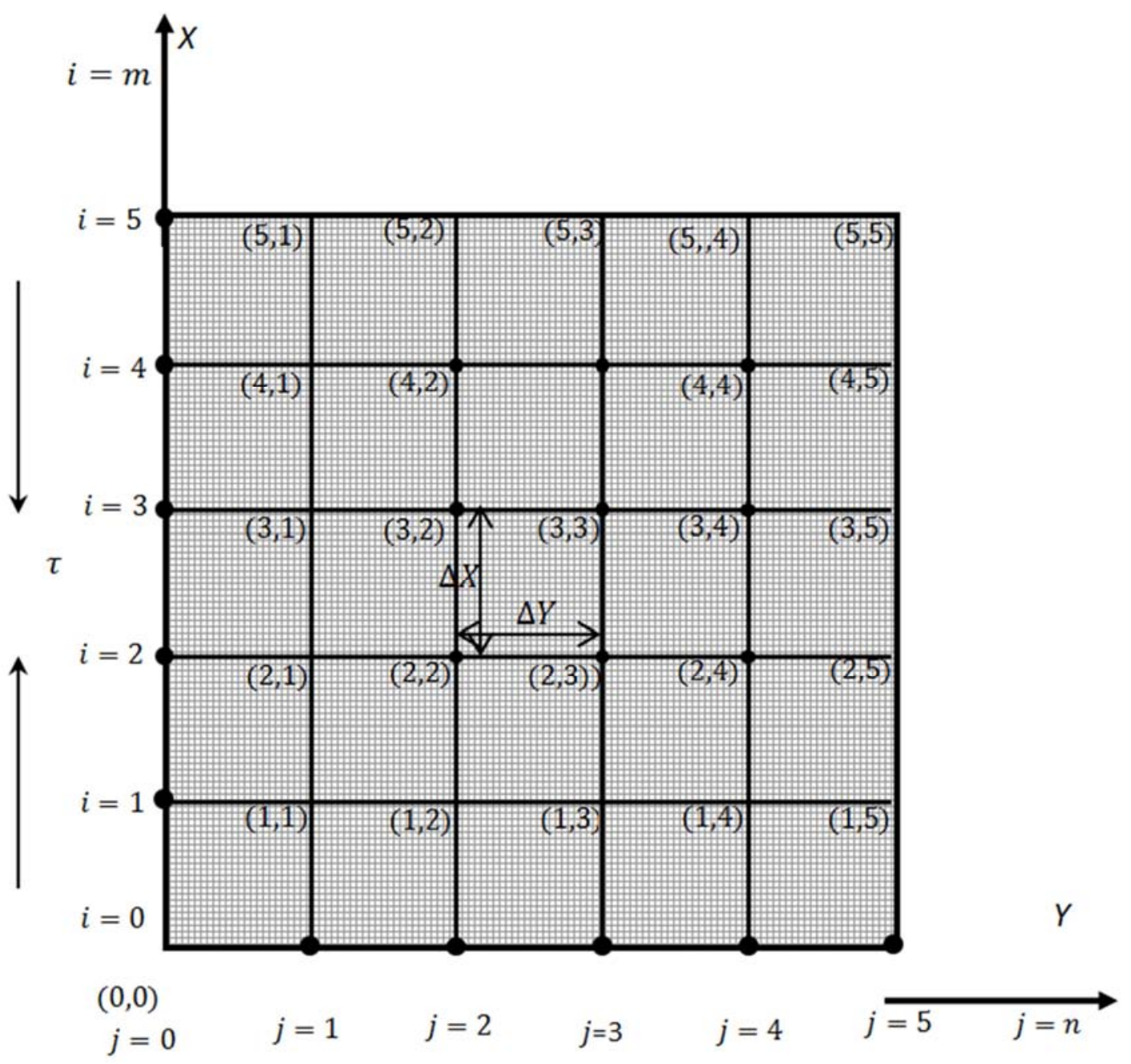

Figure 2. Finite difference space grid.

It is assumed that $\Delta X, \Delta Y$ are constant mesh sizes along $X$ and $Y$ directions respectively and taken as follows,

$$
\begin{aligned}
& \Delta X=0.5(0 \leq x \leq 100) \\
& \Delta Y=0.15(0 \leq y \leq 30)
\end{aligned}
$$

with the smaller time-step, $\Delta \tau=0.005$

Let $\mathrm{U}^{\prime}, \mathrm{V}^{\prime}, \mathrm{W}^{\prime}, \overline{\mathrm{T}}^{\prime}$ and $\overline{\mathrm{C}}^{\prime}$ denote the values of $U, V, W, \bar{T}$ and $\overline{\mathrm{C}}$ at the end of a time-step respectively. Using the explicit finite difference approximation we have, associated initial and boundary conditions (6) and (7) are solved numerically by using explicit finite difference method

To obtain the difference equations the region of the flow is divided into a grid or mesh of lines parallel to $X$ and $Y$ axes where $X$-axis is taken along the plate and $Y$-axis is normal to the plate. Here consider that the plate of height $X_{\max }=100$ i.e. $X$ varies from 0 to 100 and regard $Y_{\max }(=30)$ as corresponding to $Y \rightarrow \infty$ i.e. $Y$ varies from 0 to 30 . There are $m=200$ and $n=200$ grid spacings in the $X$ and $Y$ directions respectively as showen in Figure 


$$
\begin{gathered}
\left(\frac{\partial \overline{\mathrm{T}}}{\partial \tau}\right)_{\mathrm{i}, \mathrm{j}}=\frac{\overline{\mathrm{T}}_{\mathrm{i}, \mathrm{j}}^{\prime}-\overline{\mathrm{T}}_{\mathrm{i}, \mathrm{j}}}{\Delta \tau},\left(\frac{\partial \overline{\mathrm{T}}}{\partial \mathrm{X}}\right)_{\mathrm{i}, \mathrm{j}}=\frac{\overline{\mathrm{T}}_{\mathrm{i}, \mathrm{j}}-\overline{\mathrm{T}}_{\mathrm{i}-1, \mathrm{j}}}{\Delta \mathrm{X}},\left(\frac{\partial \overline{\mathrm{T}}}{\partial \mathrm{Y}}\right)_{\mathrm{i}, \mathrm{j}}=\frac{\overline{\mathrm{T}}_{\mathrm{i}, \mathrm{j}+1}-\overline{\mathrm{T}}_{\mathrm{i}, \mathrm{j}}}{\Delta \mathrm{Y}}, \\
\left(\frac{\partial^{2} \overline{\mathrm{T}}}{\partial \mathrm{Y}^{2}}\right)_{\mathrm{i}, \mathrm{j}}=\frac{\overline{\mathrm{T}}_{\mathrm{i}, \mathrm{j}+1}-2 \overline{\mathrm{T}}_{\mathrm{i}, \mathrm{j}}+\overline{\mathrm{T}}_{\mathrm{i}, \mathrm{j}-1}}{(\Delta \mathrm{Y})^{2}}
\end{gathered}
$$

And

$$
\begin{aligned}
& \left(\frac{\partial \overline{\mathrm{C}}}{\partial \tau}\right)_{i, j}=\frac{\overline{\mathrm{C}}_{i, j}^{\prime}-\overline{\mathrm{C}}_{\mathrm{i}, \mathrm{j}}}{\Delta \tau},\left(\frac{\partial \overline{\mathrm{C}}}{\partial \mathrm{X}}\right)_{\mathrm{i}, \mathrm{j}}=\frac{\overline{\mathrm{C}}_{\mathrm{i}, \mathrm{j}}-\overline{\mathrm{C}}_{\mathrm{i}-1, \mathrm{j}}}{\Delta \mathrm{X}},\left(\frac{\partial \overline{\mathrm{C}}}{\partial \mathrm{Y}}\right)_{\mathrm{i}, \mathrm{j}}=\frac{\overline{\mathrm{C}}_{\mathrm{i}, \mathrm{j}+1}-\overline{\mathrm{C}}_{\mathrm{i}, \mathrm{j}}}{\Delta \mathrm{Y}}, \\
& \frac{U_{i, j}-U_{i-1, j}}{\Delta X}+\frac{V_{i, j}-V_{i, j-1}}{\Delta Y}=0 \frac{U_{i, j}^{\prime}-U_{i, j}}{\Delta \tau}+U_{i, j} \frac{U_{i, j}-U_{i-1, j}}{\Delta X}+V_{i, j} \frac{U_{i, j+1}-U_{i, j}}{\Delta Y}=G_{r} \bar{T}_{i, j}^{\prime}+G_{m} \bar{C}_{i, j}^{\prime}+\frac{U_{i, j+1}-2 U_{i, j}+U_{i, j-1}}{(\Delta Y)^{2}}-M U_{i, j}
\end{aligned}
$$

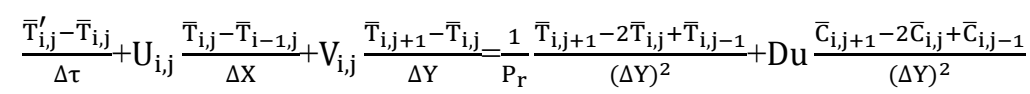

$$
\begin{aligned}
& \frac{\overline{\mathrm{C}}_{i, j}^{\prime}-\overline{\mathrm{C}}_{\mathrm{i}, \mathrm{j}}}{\Delta \tau}+\mathrm{U}_{\mathrm{i}, \mathrm{j}} \frac{\overline{\mathrm{C}}_{\mathrm{i}, \mathrm{j}}-\overline{\mathrm{C}}_{\mathrm{i}-1, \mathrm{j}}}{\Delta \mathrm{X}}+\mathrm{V}_{\mathrm{i}, \mathrm{j}} \frac{\overline{\mathrm{C}}_{\mathrm{i}, \mathrm{j}+1}-\overline{\mathrm{C}}_{\mathrm{i}, \mathrm{j}}}{\Delta \mathrm{Y}}=\frac{1}{\mathrm{~S}_{\mathrm{c}}} \frac{\overline{\mathrm{C}}_{\mathrm{i}, \mathrm{j}+1}-2 \overline{\mathrm{C}}_{\mathrm{i}, \mathrm{j}}+\overline{\mathrm{C}}_{\mathrm{i}, \mathrm{j}-1}}{(\Delta \mathrm{Y})^{2}} \\
& \mathrm{U}_{\mathrm{i}, 0}^{\mathrm{n}}=0, \mathrm{~W}_{\mathrm{i}, 0}^{\mathrm{n}}=0, \overline{\mathrm{T}}_{\mathrm{i}, 0}^{\mathrm{n}}=1, \overline{\mathrm{C}}_{\mathrm{i}, 0}^{\mathrm{n}}=1 \\
& \mathrm{U}_{\mathrm{i}, \mathrm{L}}^{\mathrm{n}}=0, \mathrm{~W}_{\mathrm{i}, \mathrm{L}}^{\mathrm{n}}=0, \overline{\mathrm{T}}_{\mathrm{i}, \mathrm{L}}^{\mathrm{n}}=0, \overline{\mathrm{C}}_{\mathrm{i}, \mathrm{L}}^{\mathrm{n}}=0 \text { where } L \rightarrow \infty \text {. }
\end{aligned}
$$$$
\frac{W_{i, j}^{\prime}-W_{i, j}}{\Delta \tau}+U_{i, j} \frac{W_{i, j}-W_{i-1, j}}{\Delta X}+V_{i, j} \frac{W_{i, j+1}-W_{i, j}}{\Delta Y}=\frac{W_{i, j+1}-2 W_{i, j}+W_{i, j-1}}{(\Delta Y)^{2}}+M W_{i, j}
$$

Here the subscripts $i$ and $j$ designate the grid points with $x$ and $y$ coordinates respectively and the superscript $n$ represents a value of time, $\tau=n \Delta \tau$ where $n=0,1,2,3, \ldots \ldots \ldots$ From the initial condition (19), the values of $U, W, \bar{T}$ and $\bar{C}$ are known at $\tau=0$. During any one time-step, the coefficients $U_{i, j}$ and $V_{i, j}$ appearing in equations (15)-(18) are treated as constants. Then at the end of any time-step $\Delta \tau$, the new temperature $\overline{\mathrm{T}}^{\prime}$, the new concentration $\overline{\mathrm{C}}^{\prime}$, the new velocity $\mathrm{U}^{\prime}$ and $\mathrm{W}^{\prime}$ at all interior nodal points may be obtained by successive applications of equations (15), (16), (17), (18), are respectively. This process is repeated in time and provided the time-step is sufficiently small, $U, W, \bar{T}$ and $\bar{C}$ should eventually converge to values which approximate the steady-state solution of equations (8)-(12). These converged solutions are shown graphically in Figure- 3 . to Figure-18.

\section{Results and Discussion}

In order to discuss the results of this problem. The approximate solution are obtain to calculate numerical values of the velocity $U$, temperature $\bar{T}$ and concentration $\bar{C}$ within the boundary layer for different values of Dufuor number $D_{u}$, magnetic parameter $M$, Grashof number $G_{r}$, Prandtal number $P_{r}$, Schmidt number $S_{c}$ with the fixed value of modified Grashof number $G_{m}$. To get the steady state solutions, the computations have been carried out up to $\tau=8$. To observe that the results of the computations, however, changes rapidly after $\tau=45$. The significance of cooling problem in nuclear engineering in connection with the cooling of reactors,. To investigate the physical situation of the problem, the solutions have been illustrated in Figure -3 to Figure -18 . The primary velocity profiles have been shown in Figures - 3, 7, 10, 12, 14 and 16. From figure-3 see that the primary velocity $U$ decreases with increases Schmidt number $S_{c}$. The effect of Prandtal number $P_{r}$ is represented by Figure-7. we see that the primary velocity $U$ decreases rapidly with increasing Prandtal number $P_{r}$. From Figure-10 we observed that the primary velocity $U$ decreases with increase of magnetic parameter $M$. In Figure-12 the primary velocity $U$ increases with increase of Grashof number $G_{r}$. The effect of modified Grashof number $G_{m}$ on the primary velocity $U$ is represented in Figure-14. It is observed that the primary velocity $U$ increases with increase of modified Grashof number $G_{m}$. In Figure-16 represent the effect of the Dufour number $D_{u}$ on Primary velocity $U$. We observe that the primary velocity $U$ increases when Dufour number $D_{u}$ increases. The secondary velocity profiles have been displayed in Figure -4, 8, 11, 13, 15 and 17. From Figure-4 we observe that the secondary velocity $W$ decreases with increase of Schmidt number $S_{c}$. In Figure-8. we observe that the Secondary velocity $W$ decreases with increase of Prandti number $P_{r}$. The effect of the Megnetic parameter $M$ on secondary velocity $W$ is represented by Figure -11. It is observed that the secondary velocity $W$ increases with increase of magnetic parameter $M$. From Figure-13 represent that the secondary velocity $W$ increases when increases of Grashof number $G_{r}$. In Figure-15 we see that the secondary velocity $W$ increases with increase of modified Grashof number $G_{m}$. From Figure- 17 we see that the secondary velocity $W$ increases with increase of Dufour number $D_{u}$. The temperature profiles have been exhibited in Figure - 5, 9 and 18. From Figure-5. we observe that Temperature $T$ increases when increases of Schmidt number $S_{c}$. The effect of Prandtl number $P_{r}$ is represented by Figure-9. we observe that the Temperature $T$ decreases with the increase of Prandtl number $P_{r}$. In Figure - 18 represent that the Temperature increases rapidly increasing of Dufour number $D_{u}$. In Figure-6. we see that the Concentration profiles $C$ decreases with increases of Schmidt number $S_{c}$. 


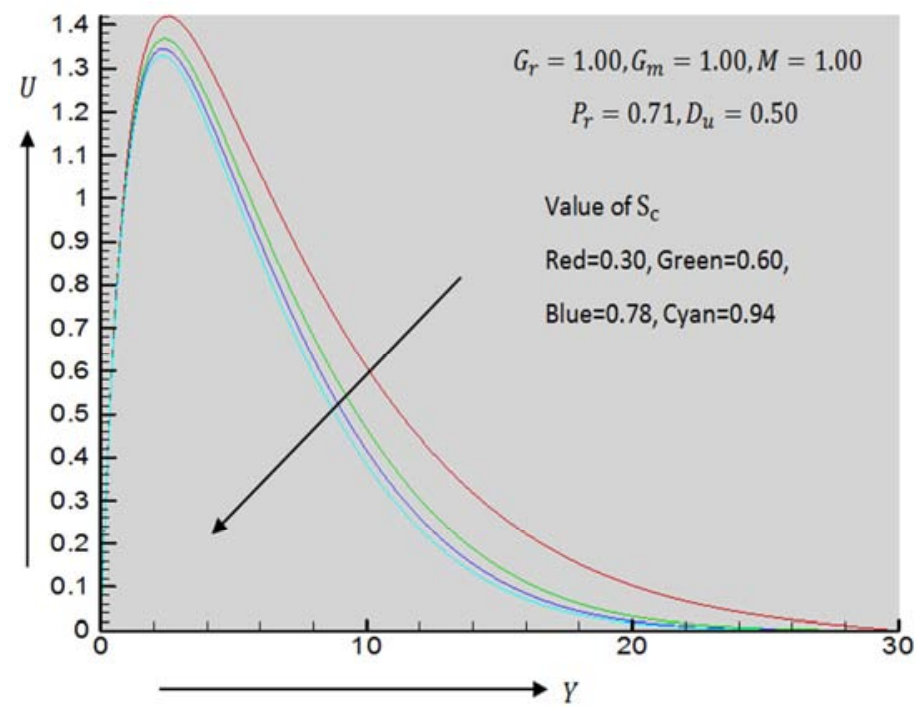

Figure 3. Primary velocity profile due to change of Schmidt number.

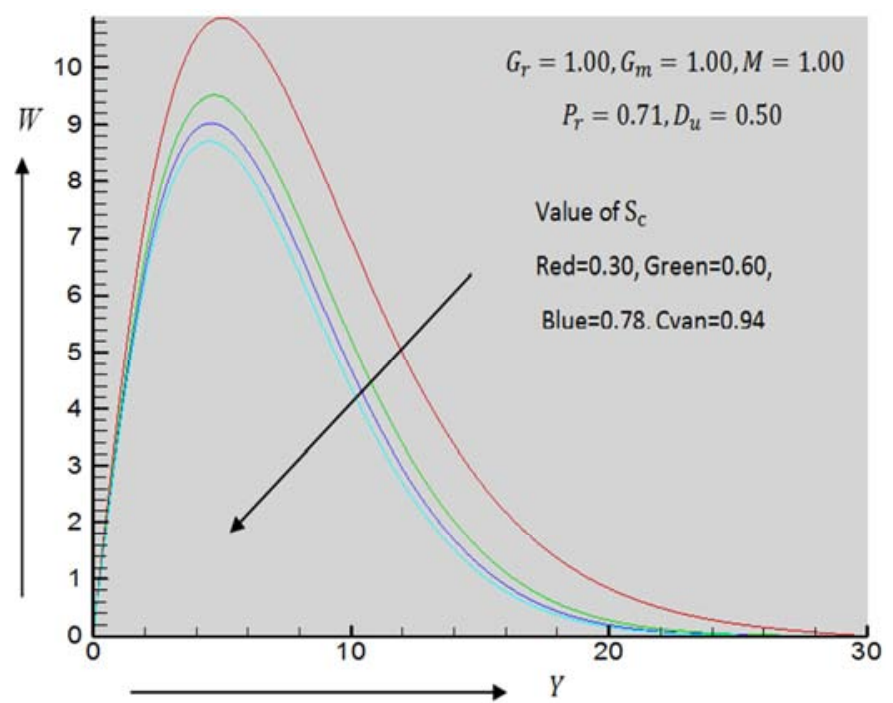

Figure 4. Secondary velocity profile due to change of Schmidt number.

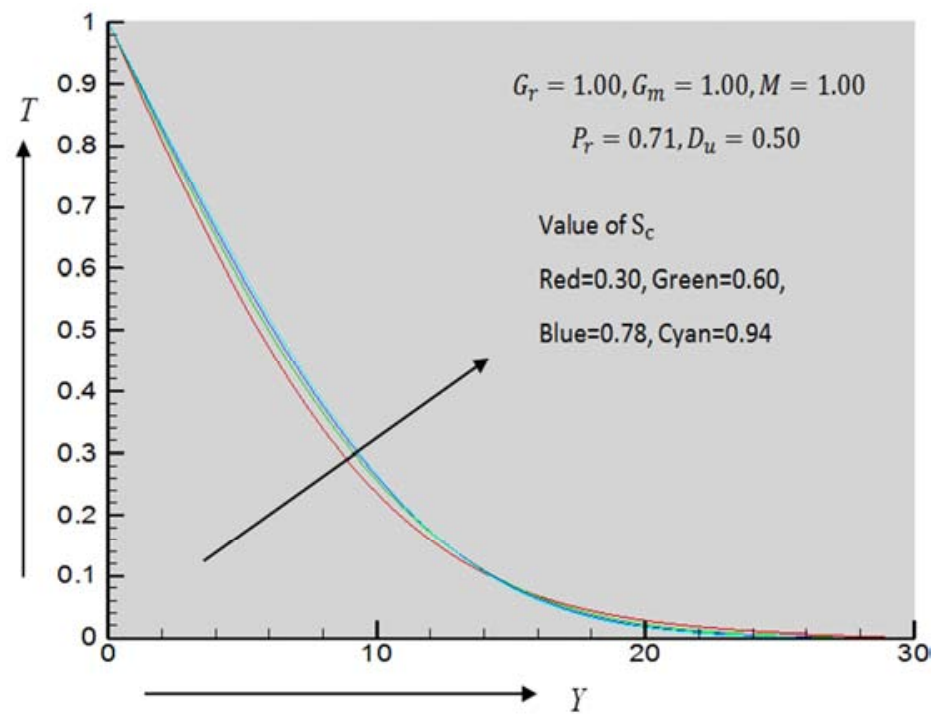

Figure 5. Temperature profile due to change of Schmidt number. 


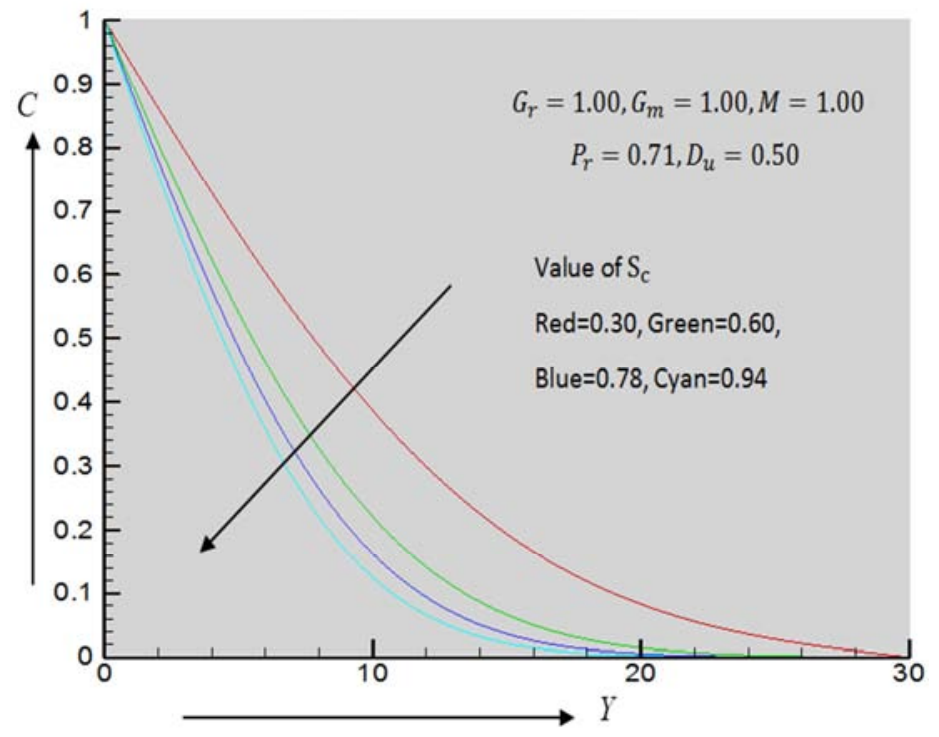

Figure 6. Concentration profile due to change of Schmidt number.

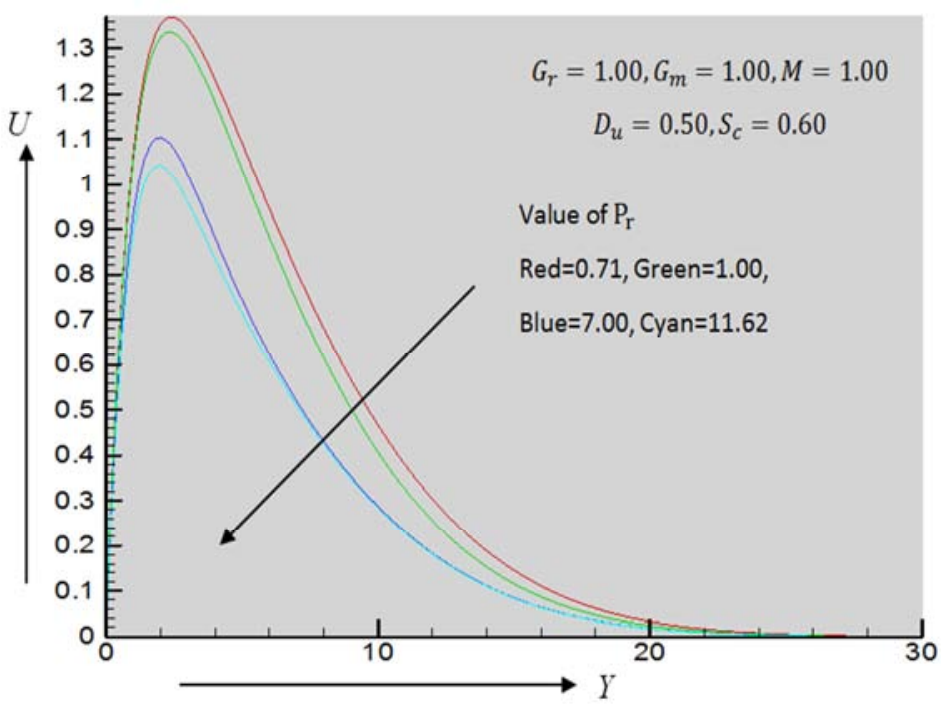

Figure 7. Primary velocity profile due to change of Prandtl number.

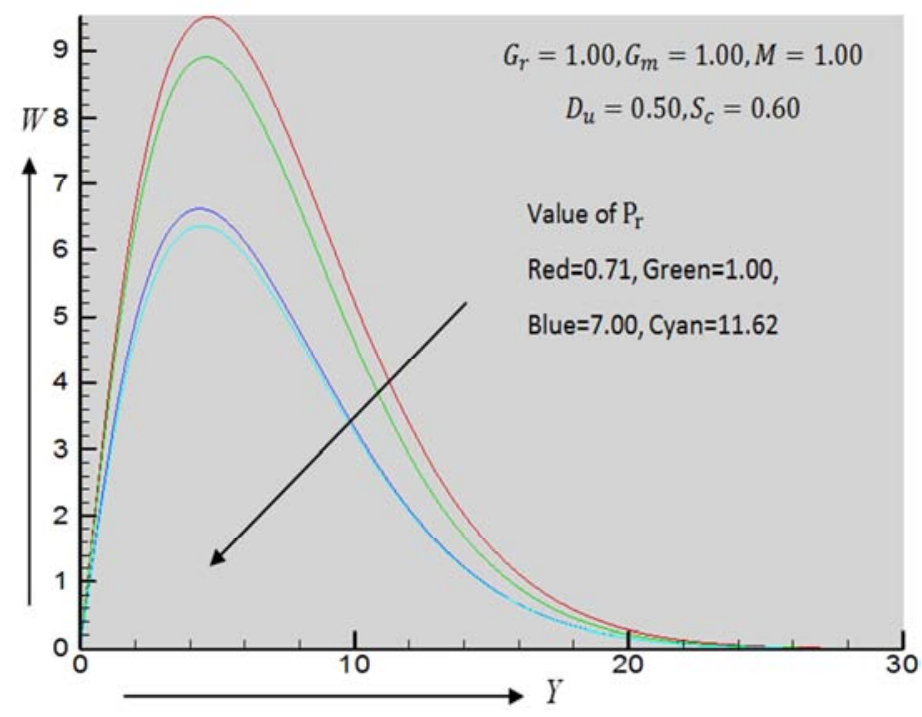

Figure 8. Secondary velocity profile due to change of Prandtl number. 


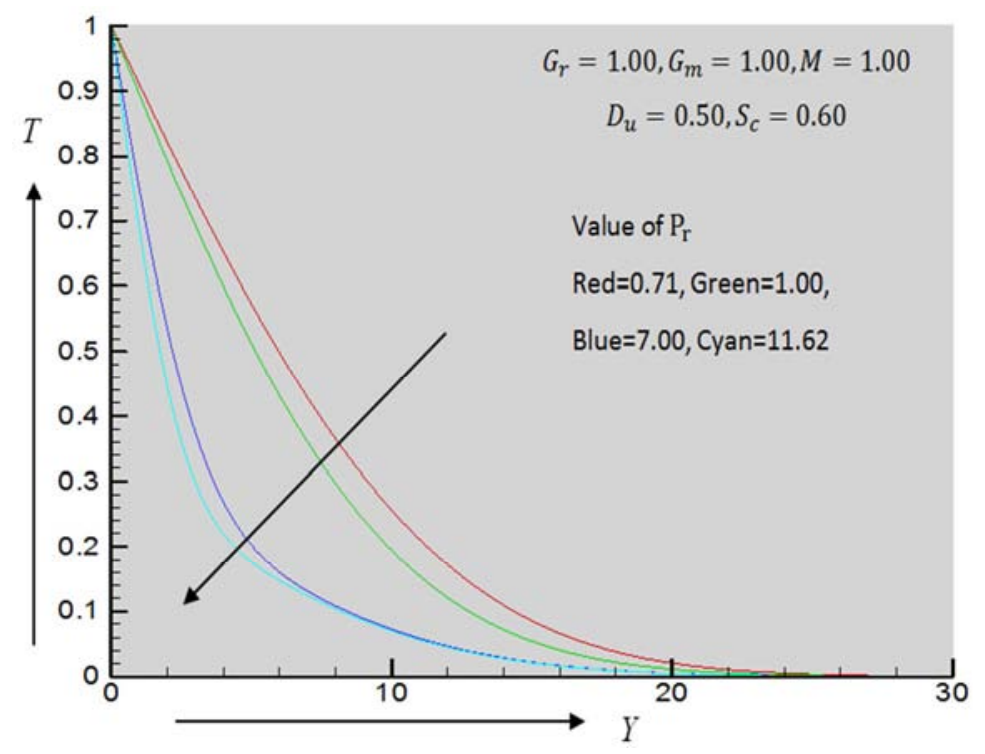

Figure 9. Temperature profile due to change of Prandtl number.

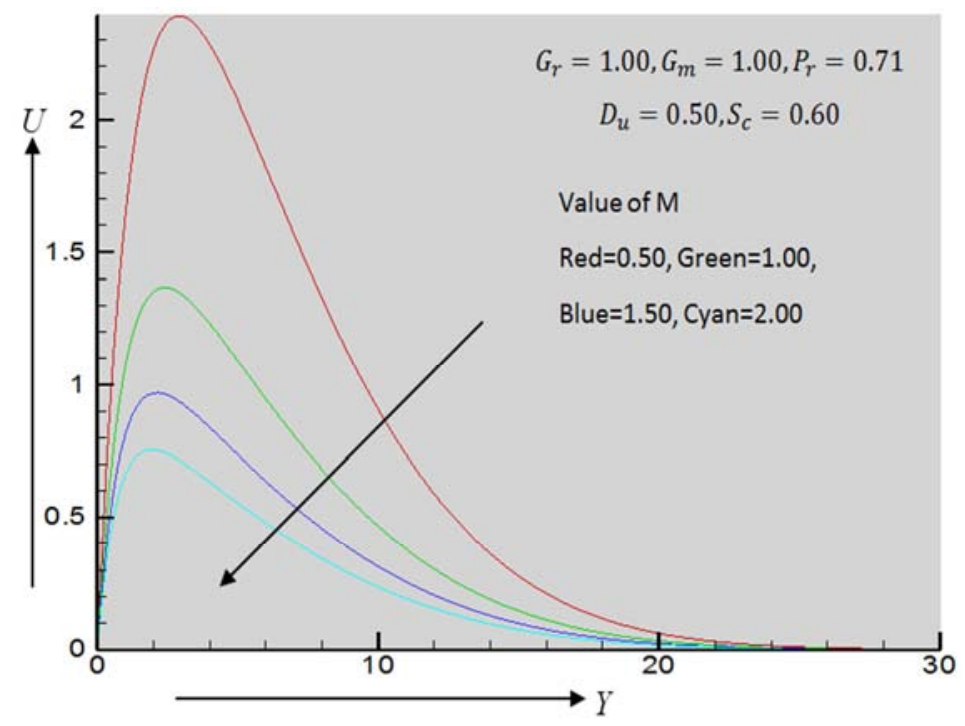

Figure 10. Primary velocity profile due to change of Magnetic parameter.

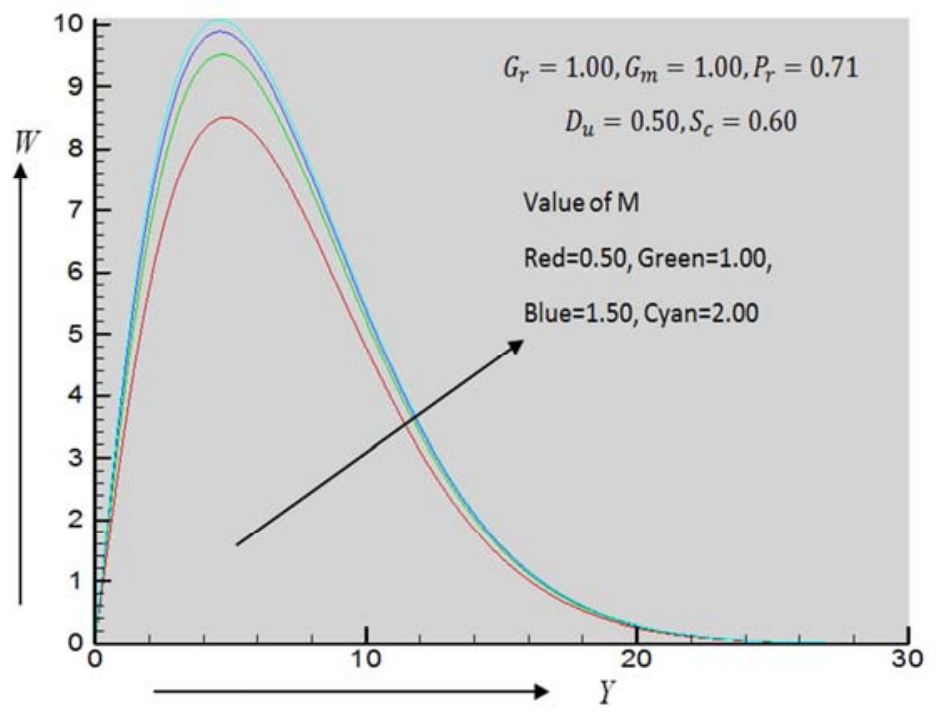

Figure 11. Secondary velocity profile due to change of Magnetic parameter. 


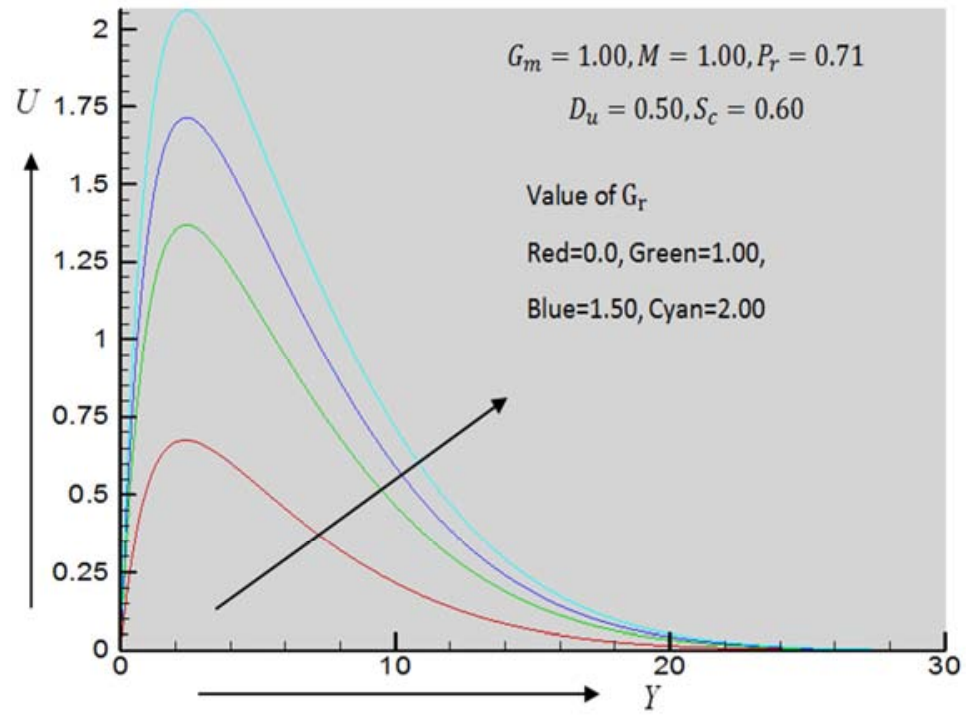

Figure 12. Primary velocity profile due to change of Grashof number.

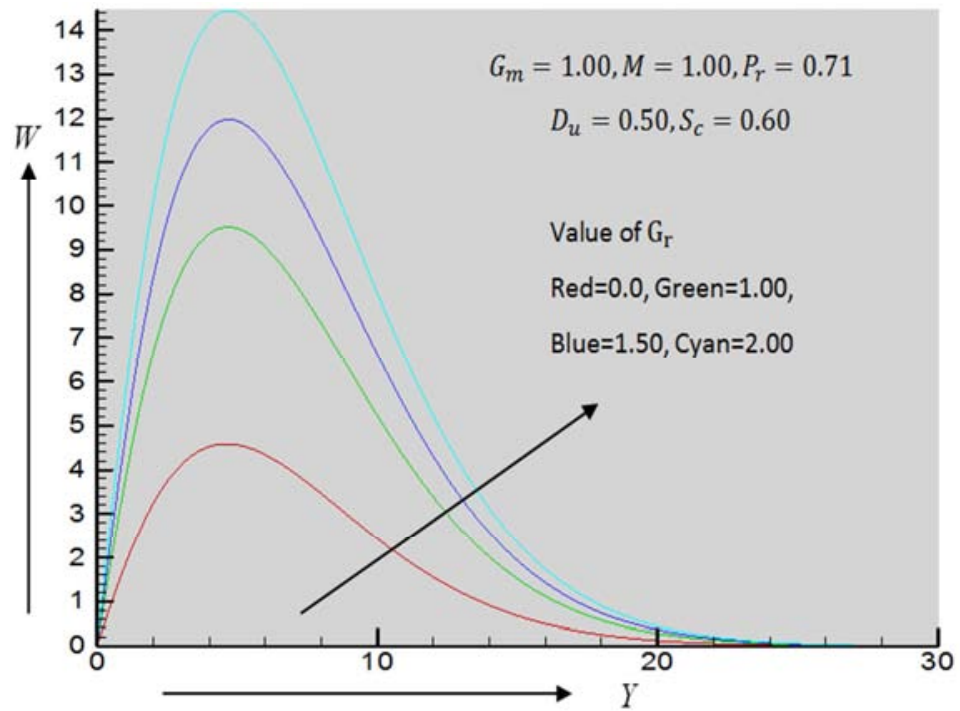

Figure 13. Secondary velocity profile due to change of Grashof number.

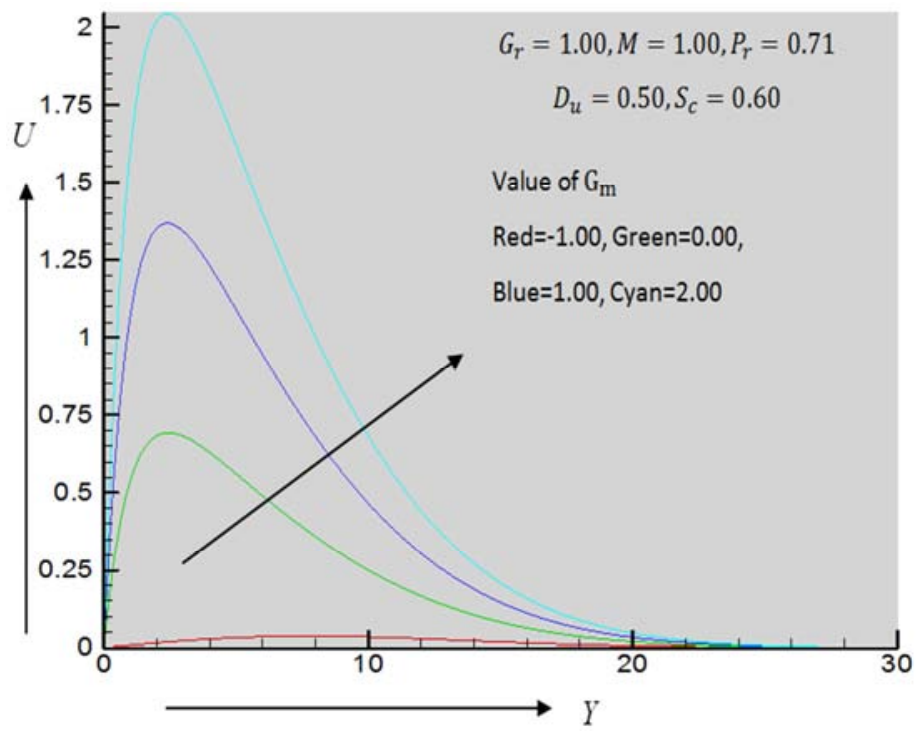

Figure 14. Primary velocity profile due to change of Modified Grashof number. 


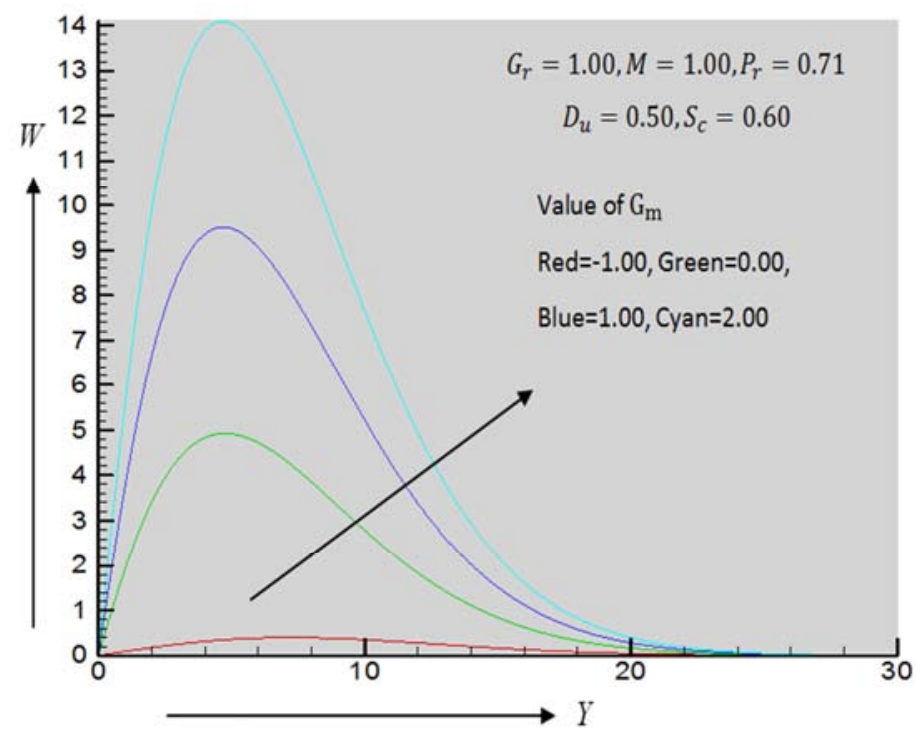

Figure 15. Secondary velocity profile due to change of Modified Grashof number.

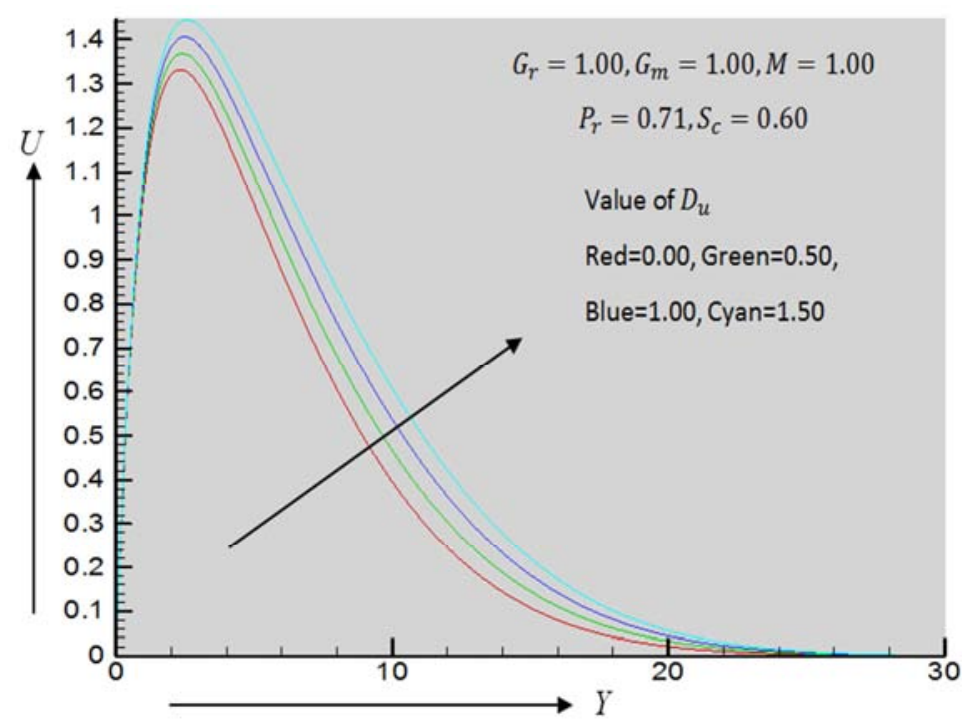

Figure 16. Primary velocity profile due to change of Dufour number.

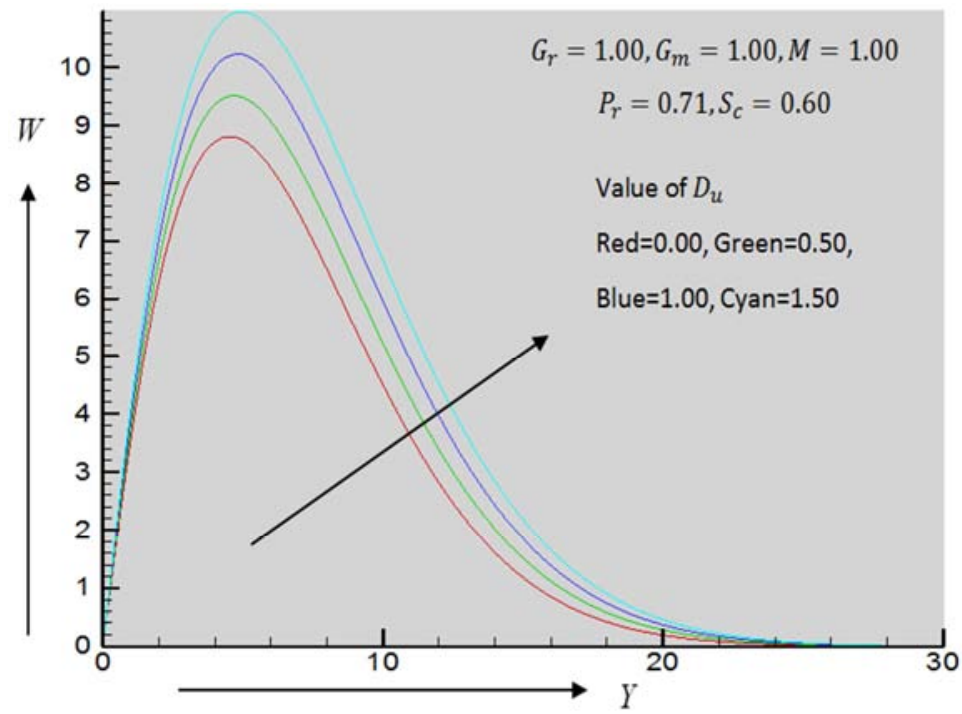

Figure 17. Secondary velocity profile due to change of Dufour number. 


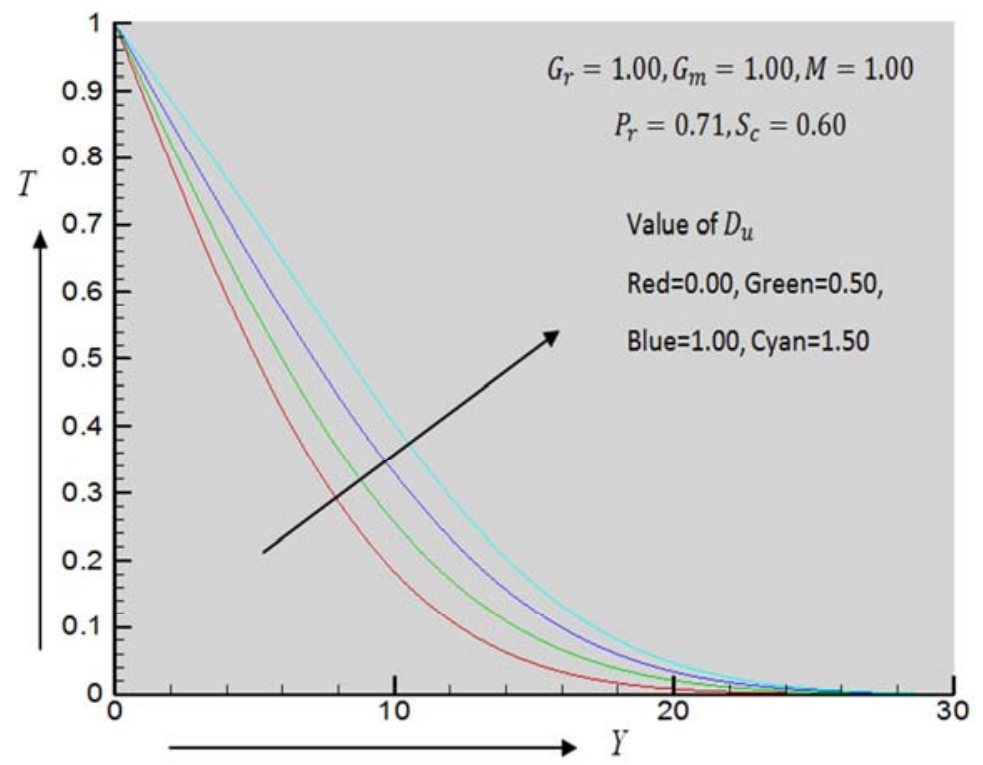

Figure 18. Temperature profile due to change of Dufour number.

\section{Conclusions}

In the present research work, the heat and mass transfer effects on MHD free convection fluid flow past a vertical porous plate. The results are given graphically to illustrate the variation of velocity, temperature and concentration with different parameters, Important findings of this investigation are given below:

The primary velocity profiles $U$ decreases with the increases of Schmidt number $\left(S_{c}\right)$ Prandtl number $\left(P_{r}\right)$ and Magnetic parameter $(M)$. On the other hand primary velocity profiles $U$ increases with the increases in Grashof number $\left(G_{r}\right)$, modified Grashof number $\left(G_{m}\right)$ and Dufour number $\left(D_{u}\right)$. The Secondary velocity profiles $W$ decreases with the increases of Schmidt number $\left(S_{c}\right)$ and Prandtl number $\left(P_{r}\right)$ as well as reverse effect with the increases of Grashof number $\left(G_{r}\right)$, modified Grashof number $\left(G_{m}\right)$ and Dufour number $\left(D_{u}\right)$ and Magnetic parameter $(M)$. The temperature increases with the increases of Schmidt number $\left(S_{c}\right)$ and Dufour number $\left(D_{u}\right)$. Whereas it decreases with an increase of Prandtl number $\left(P_{r}\right)$. The Concentration $C$ decreases with the increases of Schmidt number $\left(S_{c}\right)$

\section{Conflict of Interest}

The authors declare that they have no any conflict of interest.

\section{References}

[1] S. Idowu, M. S. Dadaand A. Jimoh, "Heat and Mass Transfer of Magneto hydrodynamic and Dissipative Fluid Flow Past a Moving Vertical Porous Plate With Variable Suction", Mathematical Theory and Modeling, Vol. 3(3), pp. 80-110, 2013.

[2] M. S. Alam, M. M. Rahman and M. A. Sattar, "MHD Free
Convective Heat and Mass Transfer Flow Past an Inclined Surface with Heat Generation", Int. J. Sc. Tech., Vol. 11(4), pp. 1-7, 2006.

[3] Mohammad Shah Alam, Mohammad Ali and Md. DelowarHossain, "Heat and Mass Transfer in MHD Free Convection Flow over an Inclined Plate with Hall Current", The International Journal of Engineering And Science, Vol. 2(7), pp. 81-88, 2013.

[4] M. Umamaheswar, S. V. K. Varmaand M. C. Raju, "Unsteady MHD Free Convective Visco-Elastic Fluid Flow Bounded by an Infinite Inclined Porous Plate in the Presence of Heat Source, Viscous Dissipation and ohmic Heating", International Journal of Advance Science and Technology, Vol. 61(5) pp. 39-52, 2013.

[5] P. R. Sharma, I. K. Dadheech and Gurminder Singh, "Heat and Mass Transfer Effects on Unsteady MHD Free Convective Flow Along a Vertical Porous Plate with Internal Heat Generation and Variable Suction", International Journal of Mathematical Archive, Vol. 3(5), pp. 2163-2172, 2012

[6] HemantPoonia and R. C. Chaudhary, "MHD free convection and mass transfer flow over an infinite vertical porous plate with viscous dissipation", Theoret. Appl. Mech., Vol. 37 (4), pp. 263-287, 2010.

[7] C. V. RamanaKumari and N. Bhaskara Reddy, "Mass Transfer Effects on Unsteady Free Convective Flow Past an Infinite Vertical Porous Plate with Variable Suction", Defence Science Journal, Vol. 45 (4), pp. 341-347, 1995.

[8] G. V. Ramana Reddy, S Mohammed Ibrahim and V. S. Bhagavan, "Similarity Transformations of Heat and Mass Transfer Effects MHD Free Convection Dissipative Fluid Flow an Inclined Porous Surface with Chemical Reaction", Journal of Naval Architecture and Marine Engineering, Vol. 11(2), pp. 157-166, 2014.

[9] K. Bhagya Lakshmi, G. S. S. Raju, P. M. Kishoreand N. V. R. V. PrasadaRao., "MHD Free Convection Flow of Dissipative Fluid Past an Exponentially Accelerated Vertical Plate", Int. Journal of Engineering Research and Applications, Vol. 3(6), pp. 689-702, 2013. 
[10] Seethamahalakshmi, G. V. Ramana Reddy and B. D. C. N. Prasad, Unsteady "MHD free convection flow and mass transfer near a moving vertical plate in the presence of thermal radiation", Advances in Applied Science Research, Vol. 2(6), pp. 261-269, 2011.

[11] V. Rajesh, "Heat Source and Mass Transfer Effects on MHD Flow of an Elasto-Viscous Fluid through a Porous Medium", International Journal of Engineering, Vol. 2(IX), pp. 206-212, 2011.

[12] N. Bhaskar Reddy, G. V. Ramana Reddy and C. V. Ramana Murthy, "Unsteady MHD Free Convective Mass Transfer Flow Past an Infinite Vertical Porous Plate with Variable Suction and Soret Effect", Int. J. of Appl. Math and Mech., Vol. 7(21), pp. 70-84, 2011.

[13] Mohammad Shah Alam, Mohammad Ali and Md. DelowarHossain, "Heat and Mass Transfer in MHD Free Convection Flow over an Inclined Plate with Hall Current", The International Journal of Engineering And Science (IJES), Vol. 2(7), pp. 81-88, 2013

[14] Joseph K. M, Daniel Sand Joseph G. M, "Unsteady MHD Couette Flow between Two Infinite Parallel Porous Plates in an Inclined Magnetic Field with Heat Transfer", International Journal of Mathematics and Statistics Invention (IJMSI), Vol. 2(3), pp. 103-110, 2014.

[15] M. S. Hossain, S. K. Paul, S. F. Ahmmed and T. Sultana,"Study on MHD Free Convection Heat and Mass Transfer Flow past a Vertical Plate in the Presence of Hall
Current", American Journal of Engineering Research (AJER), Vol. 3(12), pp. 07-14, 2014.

[16] AbdulwaheedJimoh, Moses S. Dada, Amos S. Idowu and Samson A. Agunbiade, "Numerical Study of Unsteady Free Convective Heat Transfer in Walters-B Viscoelastic Flow over an Inclined Stretching Sheet with Heat Source and Magnetic Field", The Pacific Journal of Science and Technology, Vol. 16(1), pp. 60-69, 2015.

[17] Rasulalizadeh and Alirezadarvish, "Numerical investigation of MHD free convection effects on non-Newtonian fluid over a vertical porous plate", International Conference on Mathematical Methods, Mathematical Models and Simulation in Science and Engineering, ISBN: 978-1-61804-219-4, pp. 67-71, 2014.

[18] K. Anitha, "Numerical solution of an unsteady MHD flow of a rotating fluid past an infinite vertical porous plate in the presence of radiation and chemical reaction", Electronic Journal of Mathematical Analysis and Applications, Vol. 3(2), pp. 202-214, 2015.

[19] H. S. Takhar and P. C. Ram, Effects of Hall current on hydromagnetic free convection flow through a porous medium, Astrophysics and Space Science, 192(1992) 45-51.

[20] B. K. Sharma, A. K. Jha and R. C. Chaudhary, Hall effect on MHD mixed convective flow of a viscous incompressible fluid past a vertical porous plate immersed in porous medium with heat source/sink, Journal of Physics, 52(5) (2007) 487503. 